\title{
EL NUEVO INSTITUTO DE HISTORIA DE LA CIENCIA Y LA TÉCNICA, DE VALLADOLID, Y LAS CONTRIBUCIONES DE SUS FUNDADORES
}

La fundación del Instituto de Historia de la Ciencia y de la Técnica, de Valladolid, auténtico hito de la trayectoria en España de nuestra disciplina, reúne dos singularidades. Una de ellas consiste en ser el primer instituto histórico-científico español surgido a partir de la investigación acerca de los saberes físico-matemáticos y la técnica. La otra, en estar situado en el polo opuesto de una fundación sin raíces, meramente promotora de una labor que se intenta desarrollar en el futuro. En esta ocasión, se ha creado un Instituto que, antes de disponer de unos locales y de abrir sus puertas, tiene -dicho en términos contables- un importante «haber». El contenido de los trabajos de sus fundadores significa, en el terreno de la investigación, una novedad cualitativa de importancia paralela a la que implica la creación del Instituto en la de la institucionalización.

$\mathrm{Al}$ hacer un breve «balance» de ese «haber", es decir, de lo que han aportado dichos trabajos, pueden distinguirse tres aspectos básicos de la actividad científica y técnica española del Renacimiento: la posición social de sus cultivadores, su organización y relación con el poder, y los saberes y las realizaciones técnicas.

En el primero pueden destacarse el estudio de Mariano Esteban Piñeiro acerca de los «oficios matemáticos» (1993) y el análisis prosopográfico de los ingenieros realizado por Nicolás García Tapia (1990). Esteban Piñeiro ha ofrecido por vez primera una imagen satisfactoria de la institucionalización de las matemáticas aplicadas en la España del siglo XVI como consecuencia de la necesidad que tenía el poder real de expertos en cosmografía, arte de navegar y arte militar. Ha precisado las funciones, la continuidad, las personas que los ocuparon y la posición social que tenían, estimada principalmente a través de sus salarios, de puestos ya estudiados anteriormente, como el de «piloto mayor» de la Casa de la Contratación, de algunos confusamente conocidos hasta ahora, como el de "cosmógrafo y maestro de hacer cartas, astrolabios y otros ingenios para la navegación», y de otros muchos sobre los que circulaban errores o eran sencillamente ignorados. El estudio prosopográfico de García Tapia sobre 186 ingenieros fundamenta sólidamente sus tipos: 53,8 por ciento fueron ingenieros prácticos; 24,7 , ingenieros-arquitectos; 9,7, ingenieros teóricos; y el 11,8 por ciento restante corresponde a 22 técnicos que denomina «ingenieros ocasionales o inventores», advirtiendo que la proporción de ingenieros prácticos sería en realidad mucho mayor, «dado que de la mayor parte no ha quedado rastro documental». Su distribución por estamentos sociales desmiente un tópico muy arraigado, ya que figuran varios caballeros «que no consideraron deshonroso ejercer la profesión de ingeniero» 
y que, en su práctica totalidad, eran ingenieros teóricos, como Pedro Juan de Lastanosa y Jerónimo de Ayanz, que en sus tratados procuraron ennoblecer esta ocupación, presentándola como un «arte liberal». Había también clérigos, tanto seculares como regulares, «metidos a ingenieros», aunque la inmensa mayoría de ingenieros prácticos procedía del estado llano o eran, a lo sumo, hidalgos, sobre todo de origen cantábrico. Otra afirmación arbitraria desmentida por este análisis es la supuesta condición de extranjeros de casi todos los ingenieros que trabajaron en la España del siglo XVI. García Tapia explica el error por la celebridad de algunos ingenieros italianos residentes en España (Turriano, Spanochi, los Antonelli, etc.), por la falta de investigación histórica sobre el tema y por las confusiones en torno al vocablo «ingeniero». En su serie, 72,6 por ciento son españoles, 15,1 italianos, 6,0 alemanes, 3,8 flamencos, además de dos franceses, un griego, un inglés y un portugués.

Particularmente importantes son las aportaciones del «grupo de Valladolid» relativas a la organización de la actividad científica y técnica, de las que anotaremos solamente otros dos ejemplos. El primero se refiere a las patentes de invención, tema cuya importancia no necesita ser subrayada, pero que no había sido tenido en cuenta hasta el fundamental estudio que García Tapia le ha dedicado. A semejanza de lo que se venía haciendo en Florencia, Venecia y otras «repúblicas» italianas, en España se concedieron «cédulas de privilegio real» para invenciones que, desde el principio, se ajustaron a una fórmula jurídica integrada por tres partes: la exposición del «artificio» o «ingenio» y de sus aplicaciones, el tiempo por el que se concedía a su inventor la exclusividad de construcción y uso, y las penas señaladas para castigar a los que lo copiasen o empleasen sin permiso. Cada una iba firmada por el rey, que era quien otorgaba la patente, y era válida para todas sus posesiones, incluidas las ultramarinas. La amplia serie localizada por García Tapia, que se inicia en 1522, abarca los más diversos aspectos de la técnica, desde los relacionados con la navegación hasta «artificios» para el alumbrado, pasando por máquinas para elevar el agua, todo tipo de molinos, «ingenios» minerometalúrgicos, aparatos de destilación, hornos, procedimientos de pesca, etc. Los inventores procedían de todos los estamentos sociales, incluido el nobiliario, y entre ellos figuraron importantes personalidades científicas o técnicas como Álvaro de Bazán, Pedro Juan de Lastanosa, Gómez Pereira, Juan de Herrera y Jerónimo de Ayanz. El segundo ejemplo corresponde a la Academia de Matemáticas de Madrid, institución a la que María Isabel Vicente Maroto y Mariano Esteban Piñeiro han dedicado un estudio, sólidamente basado en las fuentes, que ha aclarado su funcionamiento y sus etapas, superando noticias imprecisas, confusiones y errores de la historiografía anterior sobre el tema. Han demostrado que su actividad fundamental fue impartir enseñanza de matemáticas y cosmografía, en especial la relacionada con los problemas náuticos. Con algunos antecedentes, fue creada a finales de 1582 e inició su actividad docente en octubre del siguiente año. Felipe II, poco antes de terminar sus dos años de estancia en Lisboa, tras convertirse 
en rey de Portugal, nombró profesores de la Academia a Juan Bautista Labaña y a Pedro Ambrosio de Ondériz. Labaña era natural de Lisboa y había ocupado el cargo de cosmógrafo del rey Sebastián de Portugal. Aparte de «leer matemáticas», el nombramiento lo puso al servicio de Felipe II «en cosas de cosmografía, geografía y topografía». Ondériz había sido discípulo de Pedro Simón Abril en su localidad natal, la villa manchega de Villanueva de los Infantes, y acababa de pasar dos años en Lisboa, perfeccionando su formación científica y comenzando a traducir al castellano las obras necesarias para la enseñanza en la nueva institución que Juan de Herrera le había indicado. Fue nombrado «para que ayude al dicho Juan Bautista a leer las dichas matemáticas y se ocupe de traducir de latín en romance algunos libros de aquella facultad». Ambos dependían directamente del rey, estaban bajo la autoridad de Juan de Herrera y, hasta 1591, dieron sus clases en un edificio cercano al alcázar real. Durante estos años, Ondériz tradujo obras de Euclides, Arquímedes y Apolonio y el tratado sobre geometría esférica de Teodosio, y de la docencia que entonces impartió Labaña se conserva la relativa al «arte de navegar». El 25 de diciembre de 1582, en la misma fecha que a Labaña y Ondériz, Felipe II tomó a su servicio al portugués «Luis Georgio» (Luis Jorge de la Barbuda), «maestro de hacer cartas de cosmografía, geografía y de marear», para «hacer las dichas cartas y todo lo demás que se le ordenare de su profesión y oficio». Aunque estaba adscrito al alcázar real y bajo las órdenes de Juan de Herrera, la información reunida por Vicente Maroto y Esteban Piñeiro demuestra que no pertenecía a la Academia de Matemáticas, sino que era uno más de los numerosos cosmógrafos que trabajaban para la Corona. También han puesto de relieve que la Academia inició una nueva etapa en 1591. Labaña marchó a Lisboa como cosmógrafo mayor del Consejo de Portugal y Ondériz fue designado cosmógrafo del Consejo de Indias, aunque permaneció como profesor principal de matemáticas de la Academia, ya que ésta pasó a depender administrativamente de dicho Consejo. El puesto de segundo profesor lo ocupó Juan Arias de Loyola, quien fue, desde la misma fecha, cronista del Consejo. El contenido de la enseñanza no varió, lo que se refleja en la obra de Ondériz sobre el «uso de los globos» o «esferas» para la determinación de las coordenadas terrestres y celestes. Su sucesor fue Julián Ferrufino (o Firrufino), quien antes había enseñado matemáticas en escuelas de artillería, pero que impartió docencia en la misma línea que sus antecesores, explicando «los cuatro libros de Euclides y la materia de Esfera». Sin embargo, tras el fallecimiento de Juan de Herrera y por iniciativa de Francisco Arias de Bobadilla, «maestre de campo general de artillería», se dieron durante el curso 159798 en los locales de la Academia enseñanzas matemáticas complementarias y otras relativas al «arte militar». Juan Cedillo Díaz, catedrático de la Universidad de Toledo, impartió «la materia de los senos»; Juan Angel, las cuestiones de hidráulica contenidas en los Eguiponderantes de Arquímedes, que Ondériz había traducido al castellano; Pedro Rodríguez de Muñiz, la «materia de escuadrones y forma de ordenar- 
los»; Cristóbal de Rojas, «fortificación», de acuerdo con su importante tratado sobre el tema. Todo parece indicar que estas enseñanzas complementarias se dieron únicamente durante el curso citado, pero las noticias imprecisas acerca de ellas habían contribuido, hasta el estudio de Vicente Maroto y Esteban Piñeiro, a tener una imagen equivocada de lo que realmente fue la Academia. También se les debe el conocimiento riguroso de su etapa final, al volver la Corte a Madrid en 1607, después de un septenio en Valladolid. Fue entonces nombrado profesor Andrés García de Céspedes, que reorganizó la enseñanza, introduciendo un plan de estudios de tres años sobre matemáticas, cosmografía y arte de navegar. Le sucedió cuatro años más tarde Juan Cedillo Díaz, tras cuyo fallecimiento, en 1625, la docencia que venía impartiendo la Academia pasó a integrarse en el Colegio Imperial de Madrid, fundado por Felipe IV esa misma fecha.

Las aportaciones más numerosas de los miembros del nuevo Instituto son las relativas a los saberes y las realizaciones técnicas. El examen sistemático de textos manuscritos y de documentos de archivo que han llevado a cabo les ha conducido a hallazgos que, sin hipérbole alguna, hay que calificar de sensacionales: la traducción castellana del De revolutionibus, de Copérnico, por Cedillo Díaz; el Astronómico Real, de Alonso de Santa Cruz; la traducción de los libros de geometría práctica, de Finé, por Girava y su ordenación por Lastanosa; la demostración de que este último es el autor de Los veintiún libros de los ingenios y de las máquinas; y las patentes de invención de Jerónimo de Ayanz. No obstante, estos descubrimientos solamente constituyen la vertiente más llamativa de los resultados de su labor. Hay que añadir el análisis de obras teóricas y prácticas que antes sólo eran meros títulos, de una amplia serie de instrumentos y métodos astrónomicos y de medida, de la corrección de cartas náuticas e instrumentos para la navegación, de molinos, de ingenios y máquinas para la construcción de edificios, de ingeniería para la elevación del agua y su abastecimiento en ciudades y jardines, etc.

Para que el nuevo Instituto tenga larga y fructífera vida bastará proseguir el camino tan brillantemente recorrido hasta su fundación. Me temo que no ha cambiado la actitud de los estamentos hegemónicos de la cultura de nuestro país frente a la investigación histórica de la actividad científica española. Por lo menos, en los medios de comunicación, en las reuniones y cursos de coste millonario y en boca de muchas autoridades académicas y mandarines culturales se encuentra lo mismo de siempre. Entre otras cosas, una reiteración, más o menos vergonzante, de los planteamientos de la «polémica de la ciencia española». En cualquier caso, superar esta vieja marginación sólo va a ser posible mediante la rigurosidad y la continuada dedicación al trabajo que el nuevo Instituto y sus fundadores representan.

José M. ${ }^{a}$ López Piñero 